\title{
Setting realistic expectations: The narrow use-case for Social Impact Bonds
}

\author{
Chris Giacomantonio ${ }^{\text {* }}$
}

\section{INTRODUCTION}

Sandra Hodzic's (2018) article in the previous issue of JCSWB identified a range of social and financial pressures faced by provincial governments across Canada, to which Social Impact Bonds (SIBs) are being considered as a response. Primarily, focusing on the case of Manitoba, Hodzic identifies reductions in federal transfers, shrinking resources, expanding elderly and newcomer populations, and priorities to improve child welfare as pressures on government to do better in social service provision in a climate of fiscal constraint. Certainly, these are real pressures, and there are no simple solutions to alleviate them. Governments need a range of tools through which to develop and fund innovative social services, and in this context, SIBs have recently arisen as a possible solution to many service-provision and up-front capitalization challenges.

However, research on SIBs has not borne out the wideranging benefits often expected from SIBs. What we have seen so far, especially in the UK-the jurisdiction that has done the most to promote the SIB model ${ }^{2}$ of financing for social innovation-is that SIBs are often cumbersome strategies that introduce substantial transaction costs relative to other commissioning approaches, while also introducing unexpected and sometimes negative effects into social service provision (Roy, McHugh, \& Sinclar, 2018). While there are certain sectors and models where SIBs have financed successful interventions, even in these cases it is unclear what benefit the SIB financing model added relative to alternative strategies of financing or funding services.

Adoption of SIBs in Canada has been slow and limited, and this is a good thing. There may be value in using SIBs under certain, rather narrow, conditions, but they ought not to be seen as solutions to a wide range of service provision problems. In the following, I will briefly outline the evidence around SIBs to date, and some of the key concerns that this evidence raises. I will then close by outlining what I believe to be the main use-case in which SIBs may make sense, recognizing that any use of SIBs needs to also address the normative concerns related to the marketization of social goods.

\section{The Evidence to Date on SIBs}

SIBs have gained popularity among a range of audiences since the establishment of the first SIB at HM Prison Peterborough in the UK in 2010. A blend of impact investing and pay-forperformance or payment-by-results $(\mathrm{P} 4 \mathrm{P} / \mathrm{PbR})$ contracting, the SIB has received a substantial amount of attention as a possible way to generate up-front capital for social interventions. Early years of optimism surrounding SIBs identified a wide range of possible benefits, including: 'risk transfer' from government to investors; 'cashable' government savings; improved performance and outcomes from service provision; enhanced performance measurement and rigorous evaluation; fostering innovation that cannot be supported in traditional public service settings; empowering service providers to better respond to client needs; and attracting private capital to finance social goods (Fraser et al., 2018a; Gustafsson-Wright, Gardiner, \& Putcha, 2015).

The evidence on the results of SIB implementations to date is too substantial to sum up comprehensively here, but there are some important overview studies such as those produced by the Brookings Institution (Gustafsson-Wright et al., 2015); the Harvard SIB Lab (Azemati et al., 2013); and the Big Lottery Fund (Ronicle, Stanworth, Hickman, \& Fox, 2014) that provide early-stage learning on the global experience with SIBs since their inception. There are also studies relating to multi-site projects, including the Commissioning Better Outcomes evaluation (Ronicle, Fox, \& Stanworth, 2016) and the Trailblazer SIBs evaluation (Fraser et al., 2018a, in which I was involved as a part of the research team) that draw out commonalities and differences across a range of SIB financing contexts, models, and interventions. While the use of SIBs continues to grow-with over 100 SIBs operating or in development in high-income nations today (GustafssonWright \& Bogglid-Jones, 2018), up from only one in 2010-the experience to date reveals some weaknesses in the model that need to be taken seriously.

Chris Giacomantonio is the Research Coordinator at the Halifax Regional Police (HRP) and an adjunct professor at Saint Mary's University and Dalhousie University in Halifax, Canada. Prior to working with HRP, Chris was a senior analyst at RAND Europe, a not-for-profit policy research institute. He was involved in the evaluation of the first-ever SIB at HMP Peterborough and has published previously on the limits of SIBs. The views expressed in this commentary are those of the author and do not necessarily reflect the views of Halifax Regional Police.

2 While outside the scope of this commentary, we should recognize that there is not a single 'SIB model', but rather a range of models that each include some of the ingredients traditionally associated with SIBs (Fraser, Tan, Kruithof et al., 2018a, p. 10-14). 
First, genuine savings may not be a likely outcome of SIBs relative to other ways of contracting or delivering a service. As a starting point underpinning many cost problems with SIBs, the transaction costs associated with establishing a SIB are probably inescapably high relative to just about any other financing or funding option (Giacomantonio, 2017; Azemati et al., 2013) because a SIB requires additional contracting relationships that are unique to the SIB model. Whether these costs (including direct costs, as well as costs related to staff time) are immediately borne by government is a rather moot point-over the long term, adept investors and service providers will pass these costs onto the government that ultimately pays for the services through outcomes-based payments. Fraser and colleagues (2018a, p. 13) conclude that "successful achievement of outcomes [under a SIB] may come at increased costs... at least in the short-to-medium term, when set-up costs are taken into account." In turn, for example, scholars from the Harvard SIB lab (Azemati et al., 2013, p. 21) have suggested that, due to the substantial "overhead costs" of SIBs including legal, evaluation, intermediary, and investor costs, "these costs are only worth incurring for a SIB contract worth at least \$20 million [USD]"-in other words, small-scale SIBs are unlikely to be cost-effective. It is worth recognizing that contracting tends to be more complicated than expected in a range of PbR schemes (National Audit Office, 2015), and these contracting complexities are only enhanced by the SIB investor and intermediary relationships, which are not present in other PbR contexts. It should also be recognized that there may be ways to reduce SIB transaction costs. For example, analysis of the Sweet Dreams SIB-financed initiative suggested that transaction costs in that particular SIB were kept low by use of a single outcome metric and the fact that an intermediary was not used, thus streamlining the contracting relationship (Loxley, 2017). SIBs still introduce certain costs (not least, the introduction of return-oninvestment payments) not present in traditional contracting or service delivery, but models where comparatively simpler structures are put in place may provide a means to reduce the unique costs associated with SIBs.

Second, the market for SIB investment has thus far been largely limited to the philanthropic sector (Warner, 2013). While many potential traditional (for-profit) investors may indicate that they would consider social impact when thinking about investments, in practice evidence suggests they are still looking for market-rate returns and are unlikely to forego financial returns for social value alone (Ormiston, Charlton, Donald, \& Seymour, 2013). While SIBs have attracted some 'new' kinds of investment into social services-for example, from high-value individuals and investment firms (Gustaffsson-Wright et al., 2015, p.37-38)—on closer inspection, most of the financial support for SIBs that has come from 'new' players has been as part of Corporate Social Responsibility (CSR) activities, subsidized or guaranteed by philanthropic capital, or supported by government incentives such as guarantees, tax relief, and top-up funding. It remains unclear whether investors interested in profit could be brought into the SIB market without such incentives, and these incentives in turn represent real resources taken from philanthropies and governments that could be used elsewhere.

Third, SIB-financed interventions have not necessarily fostered innovation to the degree intended. Many
SIB-financed initiatives have been designed based on previously established interventions rather than truly innovative service-provision models. For example, reviewing the first five years of SIB development, Gustaffson and colleagues (2015, p. 42-43) concluded that, in general, SIBs did not foster innovation in service delivery. SIBs may be one way of 'scaling up' of existing interventions or allowing delivery to new populations or in new settings, but SIBs have not demonstrated a capacity to catalyze truly novel interventions and services any better than other forms of funding or financing social services.

Fourth, and perhaps most importantly, wherever we see a SIB-financed initiative succeed (i.e., where outcomes have been achieved and end-users are better-off), we need to keep in mind that there is no compelling evidence that the SIB financing mechanism-in comparative terms, relative to any other financing, funding or contracting mechanism-was responsible for this success, other than having provided upfront capitalization (which in most cases could be achieved through other, less expensive means). This lack of evidence stems in part from the fact that there have been very few studies completed to date that have successfully compared SIB-financed interventions with similar interventions funded differently from those SIBs. Where we do have comparative evidence, the main benefits from SIBs, looking across the existing evaluations, seem to be related to (a) improving performance measurement and encouraging an 'outcomes focus', and (b) creating longer-term 'ring-fenced' funding for service providers and initiatives than has normally been provided by government contracts (see e.g., Ronicle et al., 2014; Fraser et al., 2018a).

Regarding this latter benefit, where national and local governments, particularly in the UK, had a history of providing six-month or one-year grants to support pilot initiatives, SIB financing structures would often try to guarantee funding for longer periods to allow programs to become established, learn from early years, and achieve mediumterm outcomes rather than only evaluate short-term inputs and outputs. However, we should also remain aware that perhaps the two most well-publicized SIBs in the world-at HM Prison Peterborough in the UK and Rikers Island correctional facility in the US-were both terminated earlier than expected, which brings into question the true stability of SIB financing arrangements.

Outside of the empirical evidence that should lead us to at least question the empirical value of SIBs, there exists a wider set of normative concerns and 'narratives of caution' about SIBs that have been well-established elsewhere (see Fraser, Tan, Lygarde, \& Mays, 2018b). These include the potentially destructive tendencies of 'financialization' or 'marketization' of social policy, which perpetuates a 'myth' that market theories apply in social service provision (see also Hevenstone, 2015), and treats social welfare as a problem to be solved only where there is a possible benefit to investors. There is also a risk that SIB contracts will not be transparent, as intermediaries and investors may withhold information from government and public scrutiny (Warner, 2013), which can reduce, rather than enhance, oversight-and the limits to transparency in SIB contracts were experienced by our team in the Trailblazer evaluation (Fraser et al., 2018a, p. 135). However, even steering clear of 
these wider normative concerns, the empirical case for SIBs remains uncertain at best.

\section{Going Forward: Defining the Appropriate Use-Case for SIBs}

Hodzic (2018) is correct in characterizing the SIB as a kind of loan; it can be misleading to think of SIBs like traditional bonds, for a range of reasons (Disley, Rubin, Scraggs, Burrows, \& Culley, 2011, p. 1). I have argued elsewhere (Giacomantonio, 2017) that SIBs represent a kind of conditionally forgivable loan that may serve to maximize philanthropic granting capital in cases where philanthropists are not otherwise willing to provide non-repayable grants. However, SIBs are not likely to provide a robust market for diverse sources of investment or generate competitive financial returns while also creating savings for governments.

There is no question that some SIB-financed initiatives have achieved desirable outcomes, as Hodzic's article rightly points out. However, we need to be mindful that these initiatives could have been funded or financed in a variety of ways, and that the SIB may be more-not less-expensive as a form of capitalization than other options available to governments. SIBs may 'de-risk' governments, depending on the SIB structure, as Hodzic suggests; however, the wider body of literature on SIBs has shown that risk transfer is often not as comprehensive as expected (Gustaffsson-Wright at al., 2015, p. 40), and that risk transfer between investors, governments, and providers can shift during the life of a SIB (Fraser et al., 2018a).

If we are satisfied, as we should be, that SIBs are unlikely to be money-making or savings-generating vehicles capable of fostering widespread improvement of social services, we may still be able to identify a narrow band of activity in which SIBs could serve as a useful tool in social policy development. In a recent policy brief, Khovrenkov and Kobayashi (2018) refer to a SIB as an "evidence-informed pilot" — a way of better understanding an untested intervention into a complex social issue. This is an apt characterization of the SIB's role in policy development-a tool that may make sense at a pilot stage under certain conditions.

For example, there may be interventions that are sufficiently innovative, where the likelihood of success and magnitude of potential savings to government are largely unknown, where the wider community of service providers would benefit from improved outcome measurement, where a philanthropic investor is willing to provide direct financial support (but would like some repayment if real government savings are realized), and where government would subsequently directly fund the intervention with better evidence of effectiveness (but would not otherwise fund a pilot). In these circumstances, a SIB may be an appropriate financing vehicle. Within this narrow scope-and if we maintain reasonable expectations amongst both investors and governments about the magnitude of financial and social return they can expect from SIBs-we may derive some benefit from the SIB model.

\section{AUTHOR AFFILIATIONS}

*Halifax Regional Police, Dalhousie University and Saint Mary's University, Halifax, NS, Canada.

\section{REFERENCES}

Azemati, H., Belinsky, M., Gillette, R., Liebman, J., Sellman, A., \& Wyse, A. (2013). Social Impact Bonds: Lessons learned so far. Community Development Investment Review, 9, 23-34

Disley, E., Rubin, J., Scraggs, E., Burrows, N., \& Culley, D. M. (2011). Lessons learned from the planning and early implementation of the Social Impact Bond at HMP Peterborough. Cambridge, UK: RAND Europe.

Fraser, A., Tan, S., Kruithof, K., Sim, M., Disley, E., Giacomantonio, C., .. Mays, N. (2018a). Evaluation of the social impact bond trailblazers in health and social care: Final report. London, UK: Policy Innovation Research Unit (PIRU).

Fraser, A., Tan, S., Lagarde, M., \& Mays, N. (2018b). Narratives of promise, narratives of caution: A review of the literature on Social Impact Bonds. Social Policy \& Administration, 52(1), 4-28.

Giacomantonio, C. (2017). Grant-maximizing but not money-making: A simple decision-tree analysis for social impact bonds. Journal of Social Entrepreneurship, 8(1), 47-66.

Gustafsson-Wright, E., Gardiner, S., \& Putcha, W. (2015). The potential and limitations of impact bonds: Lessons from the first five years of experience worldwide. Washington, DC: Brookings Institute.

Gustafsson-Wright, E., \& Bogglid-Jones, I. (2018). Paying for social outcomes: A review of the global impact bond market in 2017. Brookings Institution (blog post) 17 January 2018. Available online at: https://www.brookings. edu/blog/education-plus-development/2018/01/17/paying-for-socialoutcomes-a-review-of-the-global-impact-bond-market-in-2017/. Accessed 6 November 2018.

Hevenstone, D. (2015). The American myth of markets in social policy: Ideological roots of inequality. New York, NY: Palgrave MacMillan.

Hodzic, S. (2018). Government under pressure: investing in better outcomes through social impact bonds. Journal of Community Safety and WellBeing, 3(2), 43-46

Khovrenkov, I., \& Kobayashi, C. (2018). Assessing social impact bonds in Canada. Regina, SK: Johnson Shoyama Graduate School of Public Policy, Policy Brief, January 2018. Available online at: https://www. schoolofpublicpolicy.sk.ca/research/publications/policy-brief/Assessingsocial-impact-bonds-in-Canada.php. Accessed 6 November 2018.

Loxley, J. (2017). Social impact bonds and the financing of child welfare. Winnipeg, MB: Canadian Centre for Policy Alternatives.

National Audit Office (NAO). (2015). Outcome-based payment schemes: Government's use of payment by results. London, UK: National Audit Office.

Ormiston, J., Charlton, K., Donald, S. M., \& Seymour, R. G. (2015). Overcoming the challenges of impact investing: Insights from leading investors. Journal of Social Entrepreneurship, 6(3), 352-378.

Ronicle, J., Stanworth, N., Hickman, E., \& Fox, T. (2014). Social impact bonds: The state of play. London, UK: Big Lottery Fund.

Ronicle, J., Fox, T., \& Stanworth, N. (2016). Commissioning better outcomes evaluation: Update report. London, UK: Big Lottery Fund.

Roy, M. J., McHugh, N., \& Sinclair, S. (2018). A critical reflection on social impact bonds. Stanford Social Innovation Review, 1 May 2018. Available online at: https://ssir.org/articles/entry/a_critical_reflection_on_social_ impact_bonds. Accessed 6 November 2018.

Warner, M. E. (2013). Private finance for public goods: Social impact bonds Journal of Economic Policy Reform, 16(4), 303-319.
DISCLOSURES

The author declares there are no conflicts of interest. 